\title{
Heterogeneous burden of lung disease in smokers with borderline airflow obstruction

Cheryl S. Pirozzi ${ }^{*}$ DD, Tian Gu², Pedro M. Quibrera ${ }^{3}$, Elizabeth E. Carretta ${ }^{3}$, MeiLan K. Han ${ }^{4}$, Susan Murray², Christopher B. Cooper ${ }^{5}$, Donald P. Tashkin ${ }^{5}$, Eric C. Kleerup ${ }^{5}$, Igor Barjaktarevic ${ }^{5}$, Eric A. Hoffman ${ }^{6}$, Carlos H. Martinez ${ }^{2}$, Stephanie A. Christenson ${ }^{7}$ Nadia N. Hansel ${ }^{8}$, R. Graham Barr ${ }^{9}$, Eugene R. Bleecker ${ }^{10}$, Victor E. Ortega ${ }^{11}$, Fernando J. Martinez ${ }^{12}$, Richard E. Kanner ${ }^{1}$, Robert Paine $1 \mathrm{II}^{1,13}$ and for the NHLBI SubPopulations and InteRmediate Outcome Measures In COPD Study (SPIROMICS)

\begin{abstract}
Background: The identification of smoking-related lung disease in current and former smokers with normal $\mathrm{FEV}_{1}$ is complex, leading to debate regarding using a ratio of forced expiratory volume in $1 \mathrm{~s}$ to forced vital capacity (FEV $/ / F V C$ ) of less than 0.70 versus the predicted lower limit of normal (LLN) for diagnosis of airflow obstruction. We hypothesized that the discordant group of ever-smokers with $\mathrm{FEV}_{1} / \mathrm{FVC}$ between the LLN and 0.70 is heterogeneous, and aimed to characterize the burden of smoking-related lung disease in this group.
\end{abstract}

Methods: We compared spirometry, chest $\subset$ characteristics, and symptoms between 161 ever-smokers in the discordant group and 940 ever-smokers and 190 never-smokers with normal FEV ${ }_{1}$ and FEV 1 /FVC $>0.70$ in the SPIROMICS cohort. We also estimated sensitivity and specificity for diagnosing objective radiographic evidence of chronic obstructive pulmonary disease (COPD) using different FEV $1 / F V C$ criteria thresholds.

Results: The discordant group had more $C T$ defined emphysema and non-emphysematous gas trapping, lower postbronchodilator $\mathrm{FEV}_{1}$ and $\mathrm{FEF}_{25-75}$, and higher respiratory medication use compared with the other two groups. Within the discordant group, 44\% had radiographic CT evidence of either emphysema or non-emphysematous gas trapping; an $\mathrm{FEV}_{1} / \mathrm{FVC}$ threshold of 0.70 has greater sensitivity but lower specificity compared with LLN for identifying individuals with CT abnormality.

Conclusions: Ever-smokers with normal $\mathrm{FEV}_{1}$ and $\mathrm{FEV}_{1} / \mathrm{FVC}<0.70$ but $>\mathrm{LLN}$ are a heterogeneous group that includes significant numbers of individuals with and without radiographic evidence of smoking-related lung disease. These findings emphasize the limitations of diagnosing COPD based on spirometric criteria alone.

Keywords: Chronic obstructive pulmonary disease, Pulmonary function tests, Spirometry, Airway obstruction, Emphysema, Forced expiratory volume, Maximal Midexpiratory flow rate

\section{Background}

Airflow obstruction is a hallmark of chronic obstructive pulmonary disease (COPD), and by current recommendations [1] is confirmed by a reduced ratio of forced expiratory volume in $1 \mathrm{~s}\left(\mathrm{FEV}_{1}\right)$ to forced vital capacity (FVC). To simplify the diagnosis of airflow obstruction, a fixed cut-off ratio of $\mathrm{FEV}_{1} / \mathrm{FVC}\left(\mathrm{FEV}_{1} / \mathrm{FVC}<0.70\right)$ is often used instead of predicted lower limit of normal

\footnotetext{
* Correspondence: Cheryl.pirozzi@hsc.utah.edu

1 Division of Pulmonary and Critical Care Medicine, Department of Internal Medicine, University of Utah, 26 N 1900 E, Salt Lake City, UT 84132, USA Full list of author information is available at the end of the article
}

(LLN) $\left(\mathrm{FEV}_{1} / \mathrm{FVC}<\mathrm{LLN}\right)$, defined as the lower fifth percentile of a reference population. [2,3]

Because the predicted normal $\mathrm{FEV}_{1} / \mathrm{FVC}$ declines with age, a fixed cut-off ratio of $\mathrm{FEV}_{1} / \mathrm{FVC}<0.70$ has the potential for misclassification and over diagnosis in the elderly, [4-10] while using predicted LLN may better predict adverse clinical outcomes [11] and more accurately predict all-cause mortality. [4] Although there is a group of younger individuals for whom LLN is $>0.7$, a particular challenge is presented by subjects who fall in a "discordant" group with $\mathrm{FEV}_{1} / \mathrm{FVC}$ ratio $>\mathrm{LLN}$ but $<0.7$. Compared to subjects with $\mathrm{FEV}_{1} / \mathrm{FVC}>0.70$, the individuals in this

(c) The Author(s). 2018 Open Access This article is distributed under the terms of the Creative Commons Attribution 4.0 International License (http://creativecommons.org/licenses/by/4.0/), which permits unrestricted use, distribution, and 
discordant group have been found to have greater emphysema, airway wall thickening, and gas trapping, as well as greater risk for chronic obstructive pulmonary disease (COPD)-related hospitalization, emergency department visits, and mortality [12-16]. There has been recent interest in characterizing patients with mild smoking-related lung disease as evidenced by symptoms and radiographic abnormalities despite normal spirometry, $[17,18]$ highlighting the limitations of using spirometric criteria alone for diagnosis of COPD. We hypothesized that the discordant group of ever-smokers with $\mathrm{FEV}_{1} / \mathrm{FVC}$ between the LLN and 0.70 is heterogeneous, containing some individuals with smoking-related lung disease and some with changes in lung function related to aging. We address this hypothesis by characterizing clinical, radiographic and physiologic features of ever-smokers in this discordant group and comparing them with the group of individuals with $\mathrm{FEV}_{1} / \mathrm{FVC}>0.70 .^{1}$

\section{Methods \\ SPIROMICS study methods}

SPIROMICS is a multicenter prospective cohort study that has enrolled 2981 participants including never-smokers, smokers without airway obstruction and smokers with mild, moderate and severe COPD, with the goals of identifying new COPD subgroups and intermediate markers of disease progression [19]. Participants were 40-80 years old at baseline. "Smokers" were defined as current or former smokers with lifetime smoking history of greater than 20 pack-years. The study design and exclusion criteria have previously been described [19]. The research protocol was approved by the institutional review boards of all participating institutions and all participants gave written informed consent.

\section{Subjects and measure of exposure}

We analyzed data for three groups of subjects included in SPIROMICS: Group 1) current or former smokers (ever-smokers) with normal post-bronchodilator $\mathrm{FEV}_{1}$ and $\mathrm{FEV}_{1} / \mathrm{FVC}>\mathrm{LLN}$ but $<0.70$ (discordant group, $n=$ 161); Group 2) ever-smokers with normal $\mathrm{FEV}_{1}$ and $\mathrm{FEV}_{1} / \mathrm{FVC}>0.70(n=940)$; and Group 3$)$ never-smokers with normal $\mathrm{FEV}_{1}$ and $\mathrm{FEV}_{1} / \mathrm{FVC}>0.70(n=190)$. In a supplementary analysis we also compared outcomes with a Group 4) patients with $\mathrm{FEV}_{1} / \mathrm{FVC}$ in the $75 \%$ quartile of those less than LLN $(n=379)$.

\section{Pulmonary function methods}

Pulmonary function testing was performed and interpreted according to the 2005 ATS/ERS guidelines; post-bronchodilator spirometric measurements were used for analysis [20, 21]. NHANES III spirometric references values were used to calculate percent predicted values and LLN [22].

\section{Outcomes}

We compared respiratory symptoms, quality of life, medication use, CT metrics, $\mathrm{FEV}_{1} \%$ predicted, forced expiratory flow rate between 25 and $75 \%$ of $\mathrm{FVC}$ or maximum mid-expiratory flow $\left(\mathrm{FEF}_{25-75}\right), 6$ min walk distance $(6 \mathrm{MWD})$, and two prospective variables: annual $\mathrm{FEV}_{1}$ change and exacerbation rate, between the three groups. Chronic bronchitis was defined as patient reported cough with sputum for at least 3 months for $\geq 2$ years. Dyspnea was defined by the modified Medical Research Council (mMRC) dyspnea score, [23] stratified into two groups as mMRC $\geq 2$ (moderate or severe dyspnea) vs mMRC $0-1$ (mild or no dyspnea). Respiratory symptoms were also measured by the COPD Assessment Test (CAT) [24]. Quality of life was measured by the St. George's Respiratory Questionnaire (SGRQ) [25]. Medication use was defined as patient-reported regular use of inhaled bronchodilators and/or inhaled steroid. Annual $\mathrm{FEV}_{1}$ change was defined using a regression model that incorporated the total number of study visits and spirometry measurements available for each participant. Each participant had a minimum of two spirometry measurements at least 200 days apart, with follow up ranging from 266 to 1749 days. Exacerbation rate was measured as the number of patient-reported events requiring health care utilization in the first year after study enrollment.

Multidetector-row computed tomography (MDCT) scans at full inspiration and full expiration were performed at the SPIROMICS baseline visit. Emphysema was defined using a threshold of $<-950$ Hounsfield Units on full inspiration. Airway wall thickening was defined as the square root of the airway wall area for a standardized airway with an internal perimeter of $10 \mathrm{~mm}$ (Pi10) [26]. Parametric Response Mapping (PRM) was used to define functional small airways disease (fSAD), a measure of non-emphysematous gas trapping, as the percent of voxels with CT attenuation values $>-950 \mathrm{HU}$ on the inspiratory exam and $<-856 \mathrm{HU}$ on the expiratory scan, as previously described [27] using Imbio Lung Density software (Imbio, Minneapolis, MN).

\section{Statistical analysis}

Comparisons of categorical predictors across groups 1, 2 and 3 used chi-squared tests. For continuous variables, ANOVA was used to test for overall differences between the 3 groups; pairwise comparisons of continuous outcomes between any two groups were based on t-tests. [28] Multivariable linear regression was used to compare continuous measures (emphysema, fSAD, CT metrics, 6MWD, CAT score, quality of life, $\mathrm{FEV}_{1}$, and $\mathrm{FEF}_{25-75}$ ) between groups, adjusted for age, sex, race, smoking history (pack-years) and current smoking (yes/no). Multivariable logistic regression was used to compare binary 
clinical outcomes (emphysema present, fSAD present, chronic bronchitis, mMRC Dyspnea, and medication use) adjusted for the same patient characteristics described above.

Quantile regression models [29] applied to healthy never -smokers estimated the 95th percentile for PRM emphysema and, separately, the 95th percentile for PRM fSAD for a normal patient based on their age, sex, BMI and the scanner used. Hereafter, these estimated 95th percentiles will be used to define the upper limit of normal (ULN) for these PRM measures according to patient/scanner characteristics. Presence of emphysema or fSAD was defined when an individual's observed PRM emphysema percent or PRM FSAD percent was greater than the estimated ULN for a normal patient with similar patient/scanner characteristics. Sensitivity and specificity of each $\mathrm{FEV}_{1} / \mathrm{FVC}$ cut-off for identifying individuals with radiographic $\mathrm{CT}$ evidence of smoking-related lung disease manifest as either emphysema and/or fSAD were estimated.

\section{Results}

We compared the discordant group (Group 1) with ever-smokers with normal spirometry (Group 2) and never-smokers (Group 3). The characteristics of the three groups are shown in Table 1. The discordant group had more male and white participants and was older than the other two groups.

Compared with ever-smokers with $\mathrm{FEV}_{1} / \mathrm{FVC}>0.70$ (Group 2), the discordant individuals (Group 1) had lower post-bronchodilator $\mathrm{FEV}_{1} \%$ predicted $(92.1 \%$ vs 97.5\%, $p<0.001)$ and reduced $\mathrm{FEF}_{25-75} \%$ predicted $(61.2 \%$ vs $102.3 \%, \mathrm{p}<0.001)$ (Table 2, Fig. 1$)$. The two groups of ever-smokers did not differ significantly in 6MWD (437.5 vs $437.2 \mathrm{~m}, p=0.97$ ), SGRQ ( 22.5 vs 24.2 , $p=0.28$ ), or CAT score (10.7 vs $11.3, p=0.36$ ). More smokers in the discordant group reported regular use of either inhaled corticosteroids and/or bronchodilators than either ever-smokers with $\mathrm{FEV}_{1} / \mathrm{FVC}>0.70$, Group
2, (34.4\% vs. $25.1 \%, p=0.01)$ or never-smokers, Group 3 $(3.9 \%, p<0.001)$. Groups 1 and 2 did not differ in the reported incidence of chronic bronchitis or moderate or severe dyspnea indicated by mMRC score $\geq 2$. Nor did they differ with respect to $\mathrm{FEV}_{1}$ decline per year, or exacerbations per year (Table 2).

The discordant group had a modest but significantly greater percentage of lung with CT scan-defined emphysema than Group $2(2.1 \%$ vs $0.7 \%, \mathrm{p}<0.001)$ or Group 3 $(0.3 \%, \mathrm{p}<0.001)$. Individuals in the discordant group also had significantly increased PRM ASAD as compared to Groups 2 and $3(18.0 \%$ vs. $9.1 \%$ and $7.1 \%$, respectively, p $<0.001$ ), without detectable differences in airway thickness (Table 3, Fig. 1). Density plots illustrating the distribution of emphysema and small airways disease are presented in supplementary material (Additional file 1: Figure S1 and Additional file 2: Figure S2).

Using age-adjusted ULN for \% emphysema, more individuals in the discordant group met CT criteria for the presence of emphysema compared with Groups 2 and 3 (38.7\% vs. $17.4 \%(\mathrm{p}<0.001)$ and $8.2 \%(\mathrm{p}<0.001)$, respectively). Similarly, using age-adjusted ULN for PRM fSAD, more individuals in the discordant group also met CT criteria for the presence of $\mathrm{SSAD}$ compared with Groups 2 and 3 $(15.3 \%$ vs. $7.8 \%(p=0.003)$ and $2.9 \%(\mathrm{p}<0.001)$, respectively). In the discordant group, $44 \%$ of subjects had CT evidence of smoking-related lung disease, manifest as either emphysema or SSAD, compared with $20.7 \%$ (p < 0.001) of Group 2 and 9.4\% ( $\mathrm{p}<0.001)$ of Group 3 subjects. Conversely, $56 \%$ of individuals in the discordant group had CT scans without radiographic evidence of smoking-related lung disease (Table 3, Fig. 2 , Additional file 3: Figure S3).

Within the discordant group, those with CT evidence of smoking-related lung disease did not have significantly greater respiratory symptoms, $\mathrm{FEV}_{1}$ decline, exacerbations, or lower $\mathrm{FEF}_{25-75}$ compared with those without emphysema or fSAD (Table 4).

When compared to a fourth group of smokers with $\mathrm{FEV}_{1} / \mathrm{FVC}$ in the $75 \%$ quartile of those less than LLN,

Table 1 Baseline characteristics for the three groups

\begin{tabular}{|c|c|c|c|c|}
\hline Variable & $\begin{array}{l}\text { Group } 1 \\
\text { Ever-smokers, Normal FEV } 1 \text {, } \\
\frac{\text { FEV1 }}{\mathrm{FVC}}<0.7 \text { and }>\text { LLN } \\
\text { (Discordant Group) }(n=161)\end{array}$ & $\begin{array}{l}\text { Group } 2 \\
\text { Ever-smokers, Normal FEV }{ }_{1}, \\
\frac{\text { EVI } 1}{\mathrm{FVC}}>0.7 \\
(n=940)\end{array}$ & $\begin{array}{l}\text { Group } 3 \\
\text { Never-smokers, Normal FEV } 1 \\
\frac{\text { FEV } 1}{\text { FVC }}>0.7 \\
(n=190)\end{array}$ & $P$-value \\
\hline Sex (\% male) & $70.8 \%$ & $49.0 \%$ & $37.9 \%$ & $<0.001^{*}$ \\
\hline Race (\% white) & $89.4 \%$ & $68.2 \%$ & $70.7 \%$ & $<0.001^{*}$ \\
\hline Current smoker (\%) & $32.5 \%$ & $50.0 \%$ & $0 \%$ & $<0.001^{*}$ \\
\hline Age $($ mean $\pm S D)$ & $69.3 \pm 6.4$ & $60.4 \pm 9.7$ & $56.6 \pm 10.2$ & $<0.001^{\dagger}$ \\
\hline $\begin{array}{l}\text { Smoking history in } \\
\text { pack-years (mean } \pm S D \text { ) }\end{array}$ & $48.3 \pm 22.2$ & $43.1 \pm 27.3$ & Not Applicable & $0.0^{\ddagger}$ \\
\hline
\end{tabular}


Table 2 Comparison of physiologic and clinical variables between ever-smokers with normal FEV 1 and FEV $1 / F V C>L L N$ but $<0.70$ ("discordant" group), ever-smokers with normal FEV 1 and $\mathrm{FEV}_{1} / \mathrm{FVC}>0.70$, and never-smokers with normal FEV 1 and $\mathrm{FEV}_{1} / \mathrm{FVC}>0.70$

\begin{tabular}{|c|c|c|c|c|c|c|c|}
\hline \multirow[t]{2}{*}{ Clinical Outcome } & \multirow[b]{2}{*}{$\begin{array}{l}\text { Group } 1 \\
\text { Ever-smokers, } \\
\text { Normal FEV }{ }_{1,} \\
\frac{\mathrm{FEV} 1}{\mathrm{FV} C}<0.7 \\
\text { and }>\text { LLN } \\
\text { (Discordant } \\
\text { Group) } \\
(n=161)\end{array}$} & \multirow{2}{*}{$\begin{array}{l}\text { Group } 2 \\
\text { Ever-smokers, } \\
\text { Normal FEV } \\
\frac{\text { FEV1 }}{\text { FVC }}>0.7 \\
(n=940)\end{array}$} & \multirow[b]{2}{*}{$\begin{array}{l}\text { Group } 3 \\
\text { Never- } \\
\text { smokers, } \\
\text { Normal } \\
\text { FEV }_{1} \\
\frac{\mathrm{FEV} 1}{\mathrm{FVC}}>0.7 \\
(n=190)\end{array}$} & \multirow{2}{*}{$\begin{array}{l}\text { Overall } p \text {-value* } \\
\text { Unadjusted } \\
\text { (Adjusted) }\end{array}$} & \multicolumn{3}{|c|}{$P$-values for pairwise comparisons (Unadjusted) } \\
\hline & & & & & Group 1 vs. 2 & Group 1 vs. 3 & Group 2 vs. 3 \\
\hline $\mathrm{FEV}_{1} \%$ predicted & $92.1 \pm 12.0$ & $97.5 \pm 12.8$ & $102.0 \pm 11.5$ & $<0.001(<0.001)$ & $<0.001$ & $<0.001$ & $<0.001^{* *}$ \\
\hline $\mathrm{FEF}_{25-75 \%} \%$ predicted & $61.2 \pm 11.0$ & $102.3 \pm 33.4$ & $121.3 \pm 32.5$ & $<0.001(<0.001)$ & $<0.001$ & $<0.001$ & $<0.001^{* *}$ \\
\hline $6 \mathrm{MWD}(\mathrm{m})$ & $437.5 \pm 109.6$ & $437.2 \pm 97.7$ & $479.3 \pm 103.4$ & $<0.001(0.49)$ & 0.97 & $<0.001$ & $<0.001^{* *}$ \\
\hline $\begin{array}{l}\text { St George's Respiratory } \\
\text { Questionnaire Total Score }\end{array}$ & $22.5 \pm 17.4$ & $24.2 \pm 19.1$ & $8.8 \pm 10.0$ & $<0.001(<0.001)$ & 0.28 & $<0.001$ & $<0.001^{* *}$ \\
\hline COPD Assessment Test (CAT) & $10.7 \pm 7.4$ & $11.3 \pm 8.1$ & $4.7 \pm 6.0$ & $<0.001(<0.001)$ & 0.36 & $<0.001$ & $<0.001^{* *}$ \\
\hline $\begin{array}{l}\text { Use of either inhaled } \\
\text { corticosteroid or bronchodilator }\end{array}$ & $34.4 \%$ & $25.1 \%$ & $3.9 \%$ & $<0.001(<0.001)$ & 0.01 & $<0.001$ & $<0.001 \dagger$ \\
\hline Chronic bronchitis & $17.3 \%$ & $17.8 \%$ & $2.1 \%$ & $<0.001(<0.001)$ & 0.88 & $<0.001$ & $<0.001 \dagger$ \\
\hline mMRC Dyspnea score $\geq 2$ & $13.8 \%$ & $13.6 \%$ & $2.7 \%$ & $<0.001(0.007)$ & 0.95 & $<0.001$ & $<0.001 \dagger$ \\
\hline Change in $\mathrm{FEV}_{1}$ (ml/year) & $-60.5 \pm 120.5$ & $-55.2 \pm 127.5$ & $-41.2 \pm 99.7$ & $\begin{array}{l}0.32 \\
(0.94)\end{array}$ & 0.64 & 0.17 & $0.19^{* *}$ \\
\hline Exacerbation (\#/year) & $0.1 \pm 0.4$ & $0.1 \pm 0.6$ & $0.02 \pm 0.1$ & $\begin{array}{l}0.02 \\
(0.21)\end{array}$ & 0.50 & 0.13 & $0.006^{* *}$ \\
\hline
\end{tabular}

Emphysema $=\%$ of voxels with CT attenuation $<-950$ Hounsfield Units (HU) on full inspiration. Functional small airways disease $=\%$ of voxels with CT attenuation $>-950 \mathrm{HU}$ on the inspiratory exam and $<-856 \mathrm{HU}$ on the expiratory scan, as determined via dynamic image registration (Parametric Response Mapping, PRM). Airway thickening = square root of the wall area for a standardized airway with an internal perimeter of $10 \mathrm{~mm}(\mathrm{Pi} 10)$

*From likelihood ratio test comparing means of 3 groups from multivariable model with outcomes (rows) and group status as predictors adjusted for age, sex, race, smoking history (pack-years) and current smoking

${ }^{* *} p$-values from 2 sample t-test

${ }^{\dagger}$ Pairwise $p$-value form Wald test comparing means of 2 groups

Group 1: Ever-smokers, Normal FEV1, FEV1/FVC $<0.7$ and $>$ LLN

Group 2: Ever-smokers, Normal FEV1, FEV1/FVC $>0.7$

Group 3: Never-smokers, Normal FEV1, FEV1/FVC $>0.7$

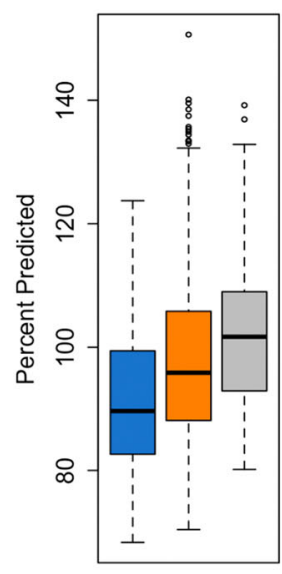

FEV1

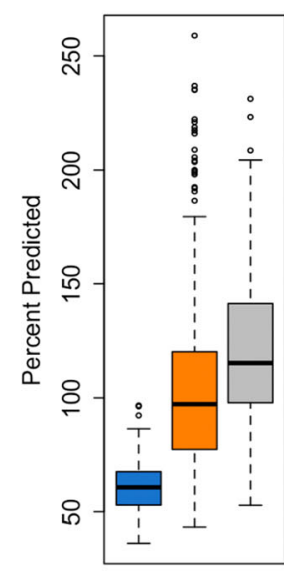

FEF25-75

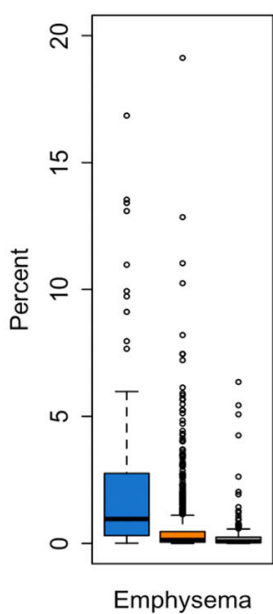

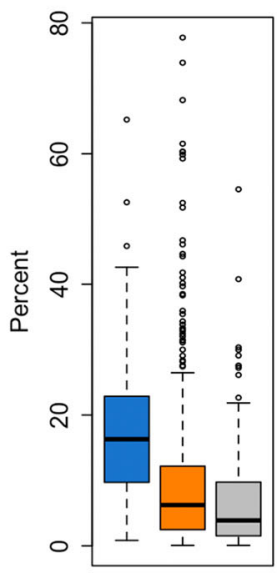

fSAD

Fig. 1 Box plots demonstrating percent of predicted forced expiratory volume in $1 \mathrm{~s}\left(\mathrm{FEV}_{1} \%\right)$, forced expiratory flow rate between 25 and $75 \%$ of forced vital capacity $\left(\mathrm{FEF}_{25-75 \%}\right)$, percent emphysema, and functional small airways disease by parametric response mapping (fSAD) in the three groups 
Table 3 Comparison of CT variables between ever-smokers with normal FEV 1 and FEV $1 / F V C>$ LLN but $<0.70$ ("discordant" group), ever-smokers with normal FEV 1 and FEV 1 FVC $>0.70$, and never-smokers with normal FEV ${ }_{1}$ and FEV $1 / F V C>0.70$

\begin{tabular}{|c|c|c|c|c|c|c|c|}
\hline \multirow[t]{2}{*}{ Variable } & \multirow[b]{2}{*}{$\begin{array}{l}\text { Group } 1 \\
\text { Ever-smokers, } \\
\text { Normal FEV } 1 \text {, } \\
\text { FEV1 }<0.7 \text { and }>\text { LLN } \\
\text { (DVC } \text { iscordant Group) } \\
(n=161)\end{array}$} & \multirow[b]{2}{*}{$\begin{array}{l}\text { Group } 2 \\
\text { Ever- } \\
\text { smokers, } \\
\text { Normal } \\
\text { FEV }_{1} \\
\frac{\mathrm{FEV} 1}{\mathrm{FVC}}>0.7 \\
(n=940)\end{array}$} & \multirow[b]{2}{*}{$\begin{array}{l}\text { Group } 3 \\
\text { Never- } \\
\text { smokers, } \\
\text { Normal } \\
\text { FEV } \\
\text { FEV1, } \\
\text { FVC }>190) \\
(n=190)\end{array}$} & \multirow[b]{2}{*}{$\begin{array}{l}\text { Overall } p \text {-value* } \\
\text { from likelihood } \\
\text { ratio test } \\
\text { comparing } \\
\text { association with } \\
\text { group status } \\
\text { Unadjusted } \\
\text { (Adjusted) }\end{array}$} & \multicolumn{3}{|c|}{ P-values for pairwise comparisons (Unadjusted) } \\
\hline & & & & & Group 1 vs. 2 & Group 1 vs. 3 & Group 2 vs. 3 \\
\hline Emphysema (\%) & $2.1 \pm 2.9$ & $0.7 \pm 2.6$ & $0.3 \pm 0.9$ & $\begin{array}{l}<0.001 \\
(<0.001)\end{array}$ & $<0.001$ & $<0.001$ & $<0.001^{* *}$ \\
\hline Functional small airways disease (\%) & $18.0 \pm 10.6$ & $9.1 \pm 10.0$ & $7.1 \pm 8.3$ & $\begin{array}{l}<0.001 \\
(<0.001)\end{array}$ & $<0.001$ & $<0.001$ & $<0.001^{* *}$ \\
\hline Airway wall thickening (Pi10) & $3.70 \pm 0.01$ & $3.71 \pm 0.00$ & $3.69 \pm 0.01$ & $\begin{array}{l}<0.001 \\
(0.17)\end{array}$ & 0.41 & 0.01 & $<0.001^{* *}$ \\
\hline Emphysema present > ULN & $38.7 \%$ & $17.4 \%$ & $8.2 \%$ & $\begin{array}{l}<0.001 \\
(<0.001)\end{array}$ & $<0.001$ & $<0.001$ & $0.004+$ \\
\hline $\begin{array}{l}\text { CT-defined functional small airway } \\
\text { abnormality (fSAD) present > ULN }\end{array}$ & $15.3 \%$ & $7.8 \%$ & $2.9 \%$ & $\begin{array}{l}<0.001 \\
(0.03)\end{array}$ & 0.003 & $<0.001$ & $0.03+$ \\
\hline Either emphysema or fSAD present & $44 \%$ & $20.7 \%$ & $9.4 \%$ & $<0.001(<0.001)$ & $<0.001$ & $<0.001$ & $<0.001 \dagger$ \\
\hline Both emphysema and fSAD present & $10 \%$ & $4.5 \%$ & $1.8 \%$ & $0.002(0.23)$ & 0.007 & 0.005 & $0.11+$ \\
\hline
\end{tabular}

Presence of emphysema $=\geq$ upper limit of normal (ULN); Presence of $f S A D=\geq$ upper limit of normal (ULN). Emphysema $=\%$ of voxels with CT attenuation <-950 Hounsfield Units (HU) on full inspiration. Functional small airways disease $=\%$ of voxels with CT attenuation $>-950 \mathrm{HU}$ on the inspiratory exam and $<-856 \mathrm{HU}$ on the expiratory scan, as determined via dynamic image registration (Parametric Response Mapping, PRM) *From likelihood ratio test comparing means of 3 groups from multivariable model with outcomes (rows) and group status as predictors adjusted for age, sex, race, smoking history (pack-years) and current smoking

**P-value from 2 sample t test

${ }^{\dagger}$ Pairwise $p$-value form Wald test comparing means of 2 groups

Group 1: Ever-smokers, Normal FEV1, FEV1/FVC $<0.7$ and $>$ LLN

- Group 2: Ever-smokers, Normal FEV1, FEV1/FVC $>0.7$

Group 3: Never-smokers, Normal FEV1, FEV1/FVC $>0.7$

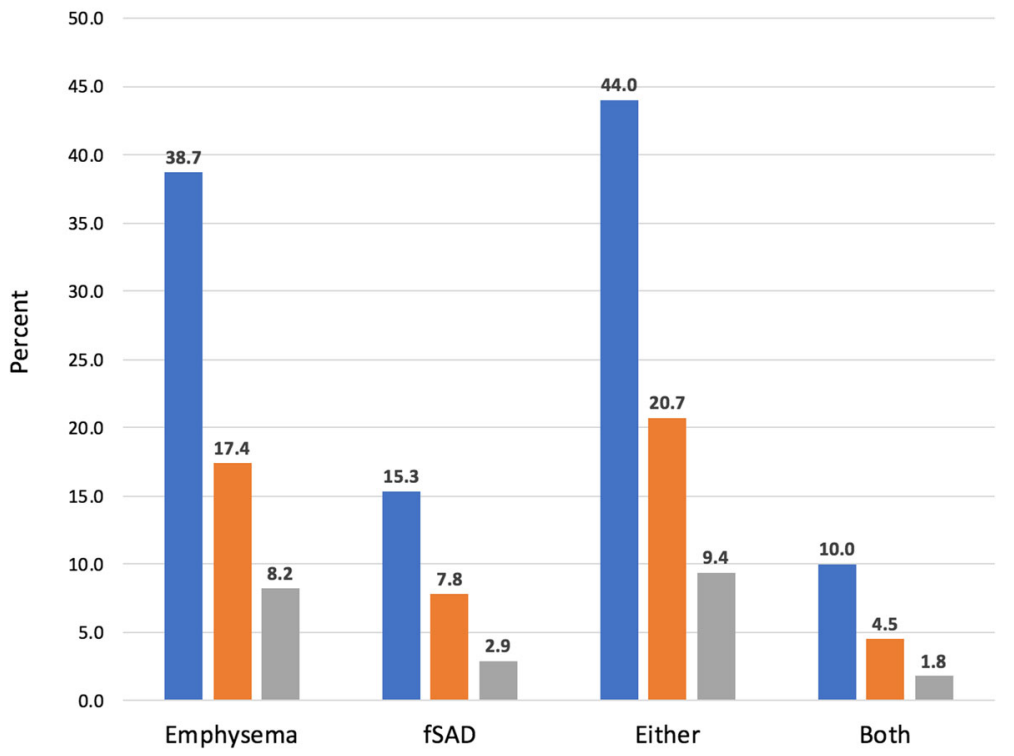

Fig. 2 Percent of patients in each group with emphysema and functional small airways disease (fSAD) present greater than the age-adjusted upper limit of normal (ULN) as measured by parametric response mapping (PRM) on chest CT 
Table 4 Comparison of prospective $\mathrm{FEV}_{1}$ decline, exacerbation rate and respiratory symptoms between those in the discordant group (Ever-smokers with normal FEV $1, F E V_{1} / F V C<0.70$ and $>L L N$ ) with $C T$ findings of emphysema or functional small airways disease, and those without

\begin{tabular}{|c|c|c|c|c|}
\hline & \multicolumn{4}{|c|}{ Ever-smokers with normal $\mathrm{FEV}_{1}, \mathrm{FEV}_{1} / \mathrm{FVC}<0.70$ and $>$ LLN (discordant group, $n=161$ ) } \\
\hline & $\begin{array}{l}\text { With fSAD or } \\
\text { emphysema (44\%) }\end{array}$ & Without fSAD or emphysema (56\%) & $\begin{array}{l}\text { *Adjusted } \\
p \text {-value }\end{array}$ & $\begin{array}{l}\text { Unadjusted } \\
p \text {-value }\end{array}$ \\
\hline Annual change in $\mathrm{FEV}_{1}$ (ml/year) & $-65.6 \pm 113.0$ & $-59.8 \pm 130.6$ & 0.26 & 0.79 \\
\hline Exacerbation (\#/year) & $0.13 \pm 0.42$ & $0.06 \pm 0.24$ & 0.90 & 0.25 \\
\hline COPD Assessment Test (CAT) & $11.43 \pm 7.44$ & $9.88 \pm 7.25$ & 0.55 & 0.22 \\
\hline Chronic bronchitis (\%) & $14.3 \pm 35.3$ & $18.3 \pm 38.9$ & 0.58 & 0.52 \\
\hline $\mathrm{FEF}_{25-75 \%} \%$ predicted & $60.0 \pm 11.6$ & $62.2 \pm 10.7$ & 0.87 & 0.24 \\
\hline
\end{tabular}

*Multivariate model adjusting for age, gender, race, pack year, and current smoking status

the discordant group had higher $\mathrm{FEV}_{1}$ and $\mathrm{FEF}_{25-75 \%}$, fewer respiratory symptoms and exacerbations, less airway wall thickness and fewer \% of people with fSAD, however did not differ in the amount of emphysema or $\mathrm{FEV}_{1}$ decline (Additional file 4: Tables S1, S2 and S3).

A history of smoking had a significant association with symptoms in groups defined by either $\mathrm{FEV}_{1} / \mathrm{FVC}$ threshold compared to never-smokers. When compared with never-smokers without airflow obstruction, both groups of ever-smokers had more chronic bronchitis, dyspnea, respiratory symptoms as measured by CAT, and lower quality of life by SGRQ (Table 2).

Finally, we evaluated the sensitivity and specificity of the two thresholds for $\mathrm{FEV}_{1} / \mathrm{FVC}$ for identification of individuals with radiographic evidence of smoking-related lung disease (emphysema > age-adjusted ULN and/or PRM fSAD > age-adjusted ULN). A threshold of $\mathrm{FEV}_{1} / \mathrm{FVC}$ $<0.7$ had a sensitivity of 0.85 and specificity of 0.72 for identifying any radiographic abnormality. The $\mathrm{FEV}_{1} / \mathrm{FVC}$ $<$ LLN threshold had lower calculated sensitivity (0.78) and higher specificity (0.81) (Table 5$)$. Thus the absolute ratio is more sensitive, while the LLN is more specific.

\section{Discussion}

In the SPIROMICS cohort, current or former smokers with normal $\mathrm{FEV}_{1}$ who are diagnosed with COPD based on GOLD spirometric criteria, but who do not have airflow obstruction based on the LLN threshold, have more emphysema and functional small airways disease by $\mathrm{CT}$, increased use of inhaled medications, and lower mid-expiratory flow compared with current or former

Table 5 Calculated sensitivity and specificity for diagnosis of COPD defined by presence of radiographic CT evidence of smoking related lung disease, with emphysema $>$ age adjusted upper limit of normal and/or functional small airways disease $>$ ULN. $N=2972$. LLN = lower limit of normal

\begin{tabular}{lll}
\hline Diagnostic criteria & Sensitivity & Specificity \\
\hline $\mathrm{FEV}_{1} / \mathrm{FVC}<0.7$ & 0.85 & 0.72 \\
$\mathrm{FEV}_{1} / \mathrm{FVC}<\mathrm{LLN}$ & 0.78 & 0.81 \\
\hline
\end{tabular}

smokers without airway obstruction, defined by $\mathrm{FEV}_{1} /$ FVC $>0.70$. Almost half of individuals in this discordant group have $\mathrm{CT}$ evidence of smoking-related lung disease. Nevertheless, the discordant group did not have increased respiratory symptoms (chronic bronchitis, dyspnea, or CAT) or decreased exercise tolerance when compared with individuals with $\mathrm{FEV}_{1} / \mathrm{FVC}$ ratio $>0.7$.

We have focused this analysis on individuals in this discordant group for three reasons. First, in reference populations the ratio of $\mathrm{FEV}_{1} / \mathrm{FVC}$ decreases with advancing age, suggesting that use of a fixed threshold of 0.7 may inappropriately classify some individuals. Second, studies of this population may help elucidate the boundaries of normal aging in the setting of cigarette smoking. Finally, there has been recent interest in the clinical picture of smokers who may have smoking-related lung disease in the setting of little or no airflow obstruction $[17,18]$. This study contributes to the discussion in each of these three areas.

Our findings support the presence of early/mild disease among individuals in this discordant group and thus provide potential pathophysiologic explanation for previous studies demonstrating increased risk for COPD-related health effects in this group, including increased adjusted risk of death, COPD-related emergency department visits and hospitalizations [13, 15]. These studies suggest that the LLN threshold lacks sensitivity, failing to identify a number of individuals with clinically significant disease.

However, because the predicted $\mathrm{FEV}_{1} / \mathrm{FVC}$ may decline with normal age, using a fixed cut-off ratio of $\mathrm{FEV}_{1} / \mathrm{FVC}<0.70$ increases diagnosis of obstruction in the elderly, and in very old adults has the potential to classify changes associated with aging as COPD [4-9]. In a cohort of adults 80 years and older, airflow obstruction defined by $\mathrm{FEV}_{1} / \mathrm{FVC}<\mathrm{LLN}$, but not $\mathrm{FEV}_{1} / \mathrm{FVC}$ between LLN and 0.70, was associated with increased mortality [4]. Similarly, small amounts of emphysema may occur due to aging-related changes rather than as a consequence of early smoking-related disease. In the multiethnic MESA cohort, full-lung CT scans of healthy 
nonsmokers revealed a small percent of emphysema (median 1.1\%) that was increased in men and with age. [30] CT-defined functional small airway abnormality also increases with age [31]. Therefore, the predicted "normal" amount of emphysema and small airways disease increases with aging even in the absence of smoking exposure. An important question is how to distinguish between early/mild COPD and normal aging. In our study we used data from normal individuals to create age-adjusted upper limits of normal for both emphysema and PRM ASAD, suggesting that the CT abnormality we have identified in the discordant group is beyond that associated with normal aging. Our study extends previous findings by including innovative imaging parameters of small airways disease and comparisons with normal lung density [16].

We found significantly reduced $\mathrm{FEF}_{25-75 \%}$ and CT scan evidence of non-emphysematous air trapping in the discordant group. Reduction in mid-expiratory flow is generally assumed to be an indication of small airways disease [32-34]. We did not identify differences in airway wall thickness, manifest as path specific Pi10, associated with our discordant group. However, changes in lumen dimension may mask changes in wall thickening/thinning by this parameter [35]. CT air trapping is also thought to reflect small airways disease and has been associated with lower lung function and accelerated lung function decline [36, 37]. The functional small airways disease measurement using PRM helps to distinguish non-emphysematous air trapping from emphysema on CT [27]. Thus physiologic and CT scan data both point to subtle but potentially clinically important small airways abnormalities in this discordant group. Several studies have suggested that in the natural history of COPD, small airways may become narrowed or lost prior to the onset of emphysema [34, 38-40] and thus these abnormalities may be an earlier indication of smoking-related COPD. We evaluated two prospective variables: exacerbations in the first year after enrollment, and $\mathrm{FEV}_{1}$ decline over a period of up to 4 years. Though we did not detect more $\mathrm{FEV}_{1}$ decline or exacerbations in the discordant group or those with radiographic emphysema or fSAD, exacerbation rate was overall low in these patients with mild smoking-related lung disease. Longer follow up time will enhance our understanding of the significance of these mild radiographic and physiologic abnormalities as predictors of progression to COPD.

The choice of a threshold of $\mathrm{FEV}_{1} / \mathrm{FVC}$ for diagnosing airflow obstruction may depend on the goals of testing and whether a more sensitive or specific test is preferred. In the SPIROMICS cohort, using a $\mathrm{FEV}_{1} / \mathrm{FVC}$ threshold of 0.70 is more sensitive but less specific for identifying individuals with radiographic manifestations of COPD, while using LLN is more specific but less sensitive. As a screening test for early/mild disease in ever-smokers, a more sensitive test may be preferred. However, identifying airflow obstruction using either $\mathrm{FEV}_{1} / \mathrm{FVC}$ threshold will incorrectly classify individuals.

There are several important features of this study. SPIROMICS is a large multi-center cohort whose subjects are extensively characterized for symptoms, physiology and radiology. MDCT scans performed at baseline allowed detailed assessment of emphysema, air trapping, and airway wall thickness and image analysis by PRM allowed differentiation of non-emphysematous air trapping from emphysema on CT. We recognize several limitations to our study. $\mathrm{FEF}_{25-75 \%}$ is an effort-dependent measurement like $\mathrm{FEV}_{1}$ and we cannot exclude a confounding effect of limited effort or frailty. However, the subjects described in this report all had studies that met ATS criteria and had normal FVC. The specificity statistic is biased because the analysis data set is not a random sample. Additionally, never-smokers with $\mathrm{FEV}_{1} /$ $\mathrm{FVC}<0.7$ were not included in SPIROMICS and thus could not be compared in this analysis.

\section{Conclusions}

Ever-smokers who have normal $\mathrm{FEV}_{1}$ and $\mathrm{FEV}_{1} / \mathrm{FVC}$ $<0.70$ but $>$ LLN (discordant group) have on average more emphysema and small airways disease, and increased respiratory medication use compared with those with $\mathrm{FEV}_{1} / \mathrm{FVC}>0.70$. This is a heterogeneous group that includes a large number of individuals with $\mathrm{CT}$ evidence of either emphysema or non-emphysematous gas trapping, as well as many individuals without radiographic evidence of early smoking-related lung disease for whom it is likely that normal aging accounts for the apparent spirometric abnormality. The diagnosis of early/mild COPD requires a more sophisticated approach that goes beyond currently accepted spirometric criteria.

\section{Endnotes}

${ }^{1}$ Some of the results of these studies have been previously reported in the form of an abstract [41, 42].

\section{Additional files}

Additional file 1: Table S1. Baseline characteristics for the four groups. Table S2. Comparison of physiologic and clinical variables between eversmokers with normal FEV 1 and FEV 1 /FVC $>$ LLN but $<0.70$ ("discordant" group, Group 1), ever-smokers with normal FEV ${ }_{1}$ and FEV $1 / F V C>0.70$ (Group 2), never-smokers with normal FEV 1 and $\mathrm{FEV}_{1} / \mathrm{FVC}>0.70$ (Group 3) and eversmokers with $\mathrm{FEV}_{1} / \mathrm{FVC} \leq \mathrm{LLN}$ and $>75$ th quartile (Group 4). Table S3. Comparison of $\mathrm{CT}$ variables between ever-smokers with normal $\mathrm{FEV}_{1}$ and $\mathrm{FEV}_{1}$ / FVC $>$ LLN but $<0.70$ ("discordant" group, Group 1), ever-smokers with normal $\mathrm{FEV}_{1}$ and $\mathrm{FEV}_{1} / \mathrm{FVC}>0.70$ (Group 2), never-smokers with normal FEV 1 and $\mathrm{FEV}_{1} / \mathrm{FVC}>0.70$ (Group 3) and ever-smokers with $\mathrm{FEV}_{1} / \mathrm{FVC} \leq \mathrm{LLN}$ and $>75$ th quartile (Group 4). (DOCX $100 \mathrm{~kb}$ )

Additional file 2: Figure S1. Density plot of the distribution of emphysema. (PNG 58 kb) 
Additional file 3: Figure S2. Density plot of the distribution of functional small airways disease. (PNG $55 \mathrm{~kb}$ )

Additional file 4: Figure S3. Venn diagram illustrating patients within the discordant group (ever-smokers with normal FEV ${ }_{1}$ and $\mathrm{FEV}_{1} / \mathrm{FVC}>$ LLN but $<0.70$ ) who have emphysema, functional small airways disease (fSAD), and both on chest CT imaging. (PDF $34 \mathrm{~kb}$ )

Additional file 5: Heterogeneous Burden of Lung Disease in Smokers with Borderline Airflow Obstruction. (DOCX $73 \mathrm{~kb}$ )

\section{Abbreviations}

6MWD: 6 min walk distance; CAT: COPD Assessment Test; COPD: Chronic obstructive pulmonary disease; CT: Computed tomography; FEF $25-75_{\text {: Forced }}$

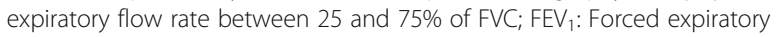
volume in $1 \mathrm{~s}$; fSAD: Functional small airways disease; FVC: Forced vital capacity; LLN: Lower limit of normal; MMRC: Modified Medical Research Council; Pi10: Square root of the airway wall area for a standardized airway with an internal perimeter of 10 mm; PRM: Parametric Response Mapping; SGRQ: St. George's Respiratory Questionnaire; ULN: Upper limit of normal

\section{Acknowledgements}

The authors thank the SPIROMICS participants and participating physicians, investigators and staff for making this research possible. More information about the study and how to access SPIROMICS data is at www.spiromics.org. We would like to acknowledge the following current and former investigators of the SPIROMICS sites and reading centers: Neil E Alexis, PhD; Wayne H Anderson, PhD; R Graham Barr, MD, DrPH; Eugene R Bleecker, MD; Richard C Boucher, MD; Russell P Bowler, MD, PhD; Elizabeth E Carretta, MPH; Stephanie A Christenson, MD; Alejandro P Comellas, MD; Christopher B Cooper, MD, PhD; David J Couper, PhD; Gerard J Criner, MD; Ronald G Crystal, MD; Jeffrey L Curtis, MD; Claire M Doerschuk, MD; Mark T Dransfield, MD; Christine M Freeman, PhD; MeiLan K Han, MD, MS; Nadia N Hansel, MD, $\mathrm{MPH}$; Annette T Hastie, PhD; Eric A Hoffman, PhD; Robert J Kaner, MD; Richard E Kanner, MD; Eric C Kleerup, MD; Jerry A Krishnan, MD, PhD; Lisa M LaVange, PhD; Stephen C Lazarus, MD; Fernando J Martinez, MD, MS; Deborah A Meyers, PhD; John D Newell Jr., MD; Elizabeth C Oelsner, MD, MPH; Wanda K O'Neal, PhD; Robert Paine, III, MD; Nirupama Putcha, MD, MHS; Stephen I. Rennard, MD; Donald P Tashkin, MD; Mary Beth Scholand, MD; J Michael Wells, MD; Robert A Wise, MD; and Prescott G Woodruff, MD, $\mathrm{MPH}$. The project officers from the Lung Division of the National Heart, Lung, and Blood Institute were Lisa Postow, PhD, and Thomas Croxton, PhD, MD.

\section{Notation of prior abstract publication/presentation}

Evidence of Clinical COPD in Smokers with Airway Obstruction Diagnosed with $\mathrm{FEV}_{1} / \mathrm{FVC}$ Ratio of Less than 0.70 but Not Less than Predicted Lower Limit of Normal. Presented at the American Thoracic Society International Conference, May 19, 2015, Denver, CO, USA.

\section{Funding}

SPIROMICS was supported by contracts from the $\mathrm{NIH} / \mathrm{NHLBI}$ (HHSN268200900013C, HHSN268200900014C, HHSN268200900015C, HHSN268200900016C, HHSN268200900017C, HHSN268200900018C HHSN268200900019C, HHSN268200900020C), which were supplemented by contributions made through the Foundation for the NIH from AstraZeneca; Bellerophon Therapeutics; Boehringer-Ingelheim Pharmaceuticals, Inc.; Chiesi Farmaceutici SpA; Forest Research Institute, Inc.; GSK; Grifols Therapeutics, Inc.; Ikaria, Inc.; Nycomed GmbH; Takeda Pharmaceutical Company; Novartis Pharmaceuticals Corporation; Regeneron Pharmaceuticals, Inc.; and Sanofi. This analysis was also supported by R01 HL122438 and K24 HL138188.

\section{Availability of data and materials}

The datasets used and/or analyzed during the current study are available from the SPIROMICS GIC coordinating center at the University of North Carolina at Chapel Hill on reasonable request.

\section{Authors' contributions}

$C P, R P$, and RK conceived and supervised the overall study. TG, PQ, EC, MKH, and $\mathrm{SM}$ participated in the statistical analysis. $\mathrm{CP}$ wrote the first draft of the manuscript. RK, MKH, CC, DT, EK, IB, EH, CM, SC, NH, GB, EB, VO, FM, TG, SM, $P Q, E C$, and RP participated in writing of the manuscript, provided important intellectual content, and read, edited, and approved the final manuscript.

\section{Ethics approval and consent to participate}

The research protocol was approved by the institutional review boards of all participating institutions and all participants gave written informed consent. Institutional review board approval reference numbers for each clinical site are available as Additional file 5.

\section{Consent for publication}

Not applicable

\section{Competing interests}

Dr. Tashkin reports personal fees from Boehringer-Ingelheim, personal fees from AstraZeneca, personal fees from Sunovion, personal fees from Theravance/Innoviva, personal fees from Mylan, outside the submitted work. Dr. Kleerup reports grants from $\mathrm{NIH}$, grants from Foundation for the $\mathrm{NIH}$, during the conduct of the study; grants from Boehringer Ingelheim, grants from Novartis, grants from Pearl/AstraZeneca, grants from Sunovion/Sepracor, outside the submitted work. Boehringer Ingelheim and GlaxoSmithKline supplied inhalers for pulmonary function testing in this study. Dr. Han reports personal fees from GSK, personal fees from BI, personal fees from AZ, nonfinancial support from Sunovion, non-financial support from Novartis, outside the submitted work. Dr. Cooper reports grants from Equinox Health Clubs, personal fees from Equinox Health Clubs, grants from Amgen, personal fees from PulmonX, GlaxoSmithKline, outside the submitted work; and works with scientific engagement for the GlaxoSmithKline Global Respiratory Franchise. Dr. Barjaktarevic reports grants from $\mathrm{NIH}$, during the conduct of the study; personal fees from Astra Zeneca, from Grifols, from CSL Behring, outside the submitted work. Dr. Hoffman is a founder and shareholder of VIDA Diagnostics, a company commercializing lung image analysis software developed, in part, at the University of lowa. Dr. Christenson reports personal fees from AstraZeneca, non-financial support from Genentech, grants from Medlmmune, outside the submitted work. Dr. Hansel reports grants and personal fees from AstraZeneca, grants and personal fees from GSK, grants from Boehringer Ingelheim, grants from $\mathrm{NIH}$, grants from COPD Foundation, outside the submitted work. Dr. Bleecker has undertaken clinical trials through his employer, Wake Forest School of Medicine and University of Arizona, for AstraZeneca, Medlmmune, Boehringer Ingelheim, Cephalon/Teva, Genentech, Johnson and Johnson (Janssen), Novartis, Regeneron, and Sanofi Genzyme, personal fees from ERB, has also served as a paid consultant for AztraZeneca, MedImmune, Boehringer Ingelheim, Glaxo Smith Kline, Novartis, Regeneron, and Sanofi Genzyme, outside the submitted work. Dr. Martinez reports grants from $\mathrm{NHLBl}$, during the conduct of the study; grants from National Institutes of Health, personal fees from Continuing Education, personal fees from Forest Laboratories, other from Janssen, personal fees from GlaxoSmithKline, personal fees from Nycomed/Takeda, personal fees from AstraZeneca, personal fees from Boehringer Ingelheim, personal fees from Bellerophon (formerly Ikaria), personal fees from Genentech, personal fees from Novartis, personal fees from Pearl, personal fees from Roche, personal fees from Sunovion, personal fees from Theravance, personal fees from CME Incite, personal fees from Annenberg Center for Health Sciences at Eisenhower, personal fees from Integritas, personal fees from InThought, personal fees from National Association for Continuing Education, personal fees from Paradigm Medical Communications, LLC, personal fees from PeerVoice, personal fees from UpToDate, personal fees from Haymarket Communications, personal fees from Western Society of Allergy and Immunology, from Proterixbio (formerly Bioscale), personal fees from Unity Biotechnology, personal fees from ConCert Pharmaceuticals, personal fees from Lucid, personal fees from Methodist Hospital, personal fees from Columbia University, personal fees from Prime Healthcare Ltd., personal fees from WebMD, personal fees from PeerView Network, personal fees from California Society of Allergy and Immunology, personal fees from Chiesi, personal fees from Puerto Rico Thoracic Society, outside the submitted work. Ms. Carretta reports funding from the National Heart, Lung, and Blood Institute, the Foundation for the NIH, Genentech, and the COPD Foundation during the conduct of the study. Dr. Paine reports grants from National Heart Lung and Blood Institute, grants from COPD Foundation, during the conduct of the study; grants from Department of Veterans Affairs, outside the submitted work.

\section{Publisher's Note}

Springer Nature remains neutral with regard to jurisdictional claims in published maps and institutional affiliations. 


\section{Author details}

'Division of Pulmonary and Critical Care Medicine, Department of Internal Medicine, University of Utah, 26 N 1900 E, Salt Lake City, UT 84132, USA. ${ }^{2}$ Department of Biostatistics, University of Michigan, Ann Arbor, MI, USA. ${ }^{3}$ Department of Biostatistics, Collaborative Studies Coordinating Center, University of North Carolina at Chapel Hill, Chapel Hill, NC, USA. ${ }^{4}$ Department of Internal Medicine, University of Michigan, Ann, MI, USA. ${ }^{5}$ Department of Medicine, UCLA David Geffen School of Medicine, Los Angeles, CA, USA. ${ }^{6}$ Department of Radiology, University of lowa, lowa City, IA, USA. ${ }^{7}$ Department of Medicine, University of California, San Francisco, CA, USA. ${ }^{8}$ Department of Medicine, Johns Hopkins University, Baltimore, MD, USA. ${ }^{9}$ Department of Medicine, Columbia University, New York, NY, USA. ${ }^{10}$ Department of Medicine, University of Arizona, Tucson, AZ, USA.

${ }^{11}$ Department of Medicine, Wake Forest University, Winston-Salem, NC, USA.

${ }^{12}$ Department of Medicine, Weill Cornell Medical College, New York, NY, USA.

${ }^{13}$ Department of Veterans Affairs Medical Center, Salt Lake City, UT, USA.

Received: 20 April 2018 Accepted: 9 October 2018

Published online: 20 November 2018

\section{References}

1. Vestbo J, Hurd SS, Agustí AG, Jones PW, Vogelmeier C, Anzueto A, Barnes PJ, Fabbri LM, Martinez FJ, Nishimura M, Stockley RA, Sin DD, RodriguezRoisin R. Global strategy for the diagnosis, management, and prevention of chronic obstructive pulmonary disease: GOLD executive summary. Am J Respir Crit Care Med. 2013;187:347-65.

2. Crapo RO, Morris AH, Gardner RM. Reference spirometric values using techniques and equipment that meet ATS recommendations. Am Rev Respir Dis. 1981;123:659-64.

3. Pellegrino R, Viegi G, Brusasco V, Crapo RO, Burgos F, Casaburi R, Coates A, van der Grinten CPM, Gustafsson P, Hankinson J, Jensen R, Johnson DC, MacIntyre N, McKay R, Miller MR, Navajas D, Pedersen OF, Wanger J. Interpretative strategies for lung function tests. Eur Respir J. 2005:948-68.

4. Turkeshi E, Vaes B, Andreeva E, Matheï C, Adriaensen W, Van Pottelbergh G, Degryse J-M. Airflow limitation by the global lungs initiative equations in a cohort of very old adults. Eur Respir J. 2015;46(1):123-32.

5. Vollmer WM, Gíslason T, Burney P, Enright PL, Gulsvik A, Kocabas A, Buist AS. Comparison of spirometry criteria for the diagnosis of COPD: results from the BOLD study. Eur Respir J. 2009;34:588-97.

6. Swanney MP, Ruppel G, Enright PL, Pedersen OF, Crapo RO, Miller MR, Jensen RL, Falaschetti E, Schouten JP, Hankinson JL, Stocks J, Quanjer PH. Using the lower limit of normal for the $\mathrm{FEV}_{1} / \mathrm{FVC}$ ratio reduces the misclassification of airway obstruction. Thorax. 2008;63:1046-51.

7. Vaz Fragoso CA, Concato J, McAvay G. Chronic obstructive pulmonary disease in older persons: a comparison of two spirometric definitions. Respiratory. 2010;104(8):1189-96.

8. Hansen JE, Sun X-G, Wasserman K. Spirometric criteria for airway obstruction: use percentage of $\mathrm{FEV}_{1} / \mathrm{FVC}$ ratio below the fifth percentile, not. CHEST. 2007;131:349-55.

9. Quanjer PH. Correctly defining criteria for diagnosing chronic obstructive pulmonary disease matters. Am J Respir Crit Care Med. 2014;189:230.

10. Vaz Fragoso CA, McAvay G, Van Ness PH, Casaburi R, Jensen RL, Maclntyre N, Gill TM, Yaggi HK, Concato J. Phenotype of Normal spirometry in an aging population. Am J Respir Crit Care Med. 2015;192:817-25.

11. van Dijk W, Tan W, Li P, Guo B, Li S, Benedetti A, Bourbeau J, CanCOLD study group. Clinical relevance of fixed ratio vs lower limit of normal of $\mathrm{FEV}_{1} / \mathrm{FVC}$ in COPD: patient-reported outcomes from the CanCOLD cohort. Ann Fam Med. 2015;13:41-8.

12. Bhatt SP, Sieren JC, Dransfield MT, Washko GR, Newell JD, Stinson DS, Zamba GKD, Hoffman EA, COPDGene Investigators. Comparison of spirometric thresholds in diagnosing smoking-related airflow obstruction. Thorax. 2014;69:409-14.

13. Mannino DM, Sonia Buist A, Vollmer WM. Chronic obstructive pulmonary disease in the older adult: what defines abnormal lung function? Thorax. 2007;62:237-41.

14. Mohamed Hoesein FAA, Zanen P, Lammers J-WJ. Lower limit of normal or $\mathrm{FEV}_{1} /$ FVC. Respir Med. 2011;105:907-15.

15. Izquierdo Alonso JL, De Lucas Ramos P, Rodríguez Glez-Moro JM. The use of the lower limit of Normal as a criterion for COPD excludes patients with increased morbidity and high consumption of health-care resources. Archivos de Bronconeumología (English Edition). 2012;48:223-8.
16. Hoesein FAAM, de Jong PA, Lammers J-WJ, Mali WP, Schmidt M, de Koning $\mathrm{HJ}$, van der Aalst C, Oudkerk M, Vliegenthart R, van Ginneken B, van Rikxoort EM, Zanen P. Computed tomography structural lung changes in discordant airflow limitation. PLoS One. 2013;8:e65177.

17. Woodruff PG, Barr RG, Bleecker E, Christenson SA, Couper D, Curtis JL, Gouskova NA, Hansel NN, Hoffman EA, Kanner RE, Kleerup E, Lazarus SC, Martinez FJ, Paine R, Rennard S, Tashkin DP, Han MK, SPIROMICS research group. Clinical significance of symptoms in smokers with preserved pulmonary function. N Engl J Med. 2016;374:1811-21.

18. Regan EA, Lynch DA, Curran-Everett D, Curtis JL, Austin JHM, Grenier PA, Kauczor H-U, Bailey WC, DeMeo DL, Casaburi RH, Friedman P, Van Beek EJR, Hokanson JE, Bowler RP, Beaty TH, Washko GR, Han MK, Kim V, Kim SS, Yagihashi K, Washington L, McEvoy CE, Tanner C, Mannino DM, Make BJ, Silverman EK, Crapo JD. Clinical and radiologic disease in smokers with Normal spirometry. JAMA Intern Med. 2015;175:1539.

19. Couper D, LaVange LM, Han M, Barr RG, Bleecker E, Hoffman EA, Kanner R, Kleerup E, Martinez FJ, Woodruff PG, Rennard S, SPIROMICS research group. Design of the Subpopulations and Intermediate Outcomes in COPD study (SPIROMICS). Thorax. 2014;69:491-4.

20. Miller MR, Hankinson J, Brusasco V, Burgos F, Casaburi R, Coates A, Crapo R, Enright $P$, van der Grinten CPM, Gustafsson P, Jensen R, Johnson DC, Maclntyre N, McKay R, Navajas D, Pedersen OF, Pellegrino R, Viegi G, Wanger J. ATS/ERS task force: standardisation of spirometry. Eur Respir J. 2005;26(2):319-38

21. Miller MR, Crapo R, Hankinson J, Brusasco V, Burgos F, Casaburi R, Coates A, Enright P, van der Grinten CPM, Gustafsson P, Jensen R, Johnson DC, MacIntyre N, McKay R, Navajas D, Pedersen OF, Pellegrino R, Viegi G, Wanger J. ATS/ERS task force: general considerations for lung function testing. Eur Respir J. 2005;26:153-61.

22. Hankinson JL, Odencrantz JR, Fedan KB. Spirometric reference values from a sample of the general U.S. population. Am J Respir Crit Care Med. 1999;159:179-87.

23. Bestall JC, Paul EA, Garrod R, Garnham R, Jones PW, Wedzicha JA. Usefulness of the Medical Research Council (MRC) dyspnoea scale as a measure of disability in patients with chronic obstructive pulmonary disease. Thorax. 1999;54:581-6.

24. Jones PW, Harding G, Berry P, Wiklund I, Chen W-H, Kline Leidy N. Development and first validation of the COPD assessment test. Eur Respir J. 2009;34:648-54.

25. Jones PW, Quirk FH, Baveystock CM, Littlejohns P. A self-complete measure of health status for chronic airflow limitation. The St. George's respiratory questionnaire. Am Rev Respir Dis. 1992;145:1321-7.

26. Nakano Y, Wong JC, de Jong PA, Buzatu L, Nagao T, Coxson HO, Elliott WM, Hogg JC, Paré PD. The prediction of small airway dimensions using computed tomography. Am J Respir Crit Care Med. 2005;171:142-6.

27. Galbán CJ, Han MK, Boes JL, Chughtai KA, Meyer CR, Johnson TD, Galbán S, Rehemtulla A, Kazerooni EA, Martinez FJ, Ross BD. Computed tomographybased biomarker provides unique signature for diagnosis of COPD phenotypes and disease progression. Nat Med. 2012;18:1711-5.

28. Welch BL. The generalization of "student"s" problem when several different population variances are involved. Biometrika. 1947;34:28.

29. Koenker R (2012). Package 'quantreg'. http://cran.r-project.org/web/ packages/quantreg/quantreg.pdf, accessed 15 Aug 2018.

30. Hoffman EA, Ahmed FS, Baumhauer H, Budoff M, Carr JJ, Kronmal R, Reddy S, Barr RG. Variation in the percent of emphysema-like lung in a healthy, nonsmoking multiethnic sample. The MESA lung study. Ann Am Thorac Soc. 2014;11:898-907.

31. Martinez $\mathrm{CH}$, Diaz AA, Meldrum C, Curtis JL, Cooper CB, Pirozzi C, Kanner RE, Paine R, Woodruff PG, Bleecker ER, Hansel NN, Barr RG, Marchetti N, Criner GJ, Kazerooni EA, Hoffman EA, Ross BD, Galbán CJ, Cigolle CT, Martinez FJ, Han MK, SPIROMICS Investigators. Age and small airway imaging abnormalities in subjects with and without airflow obstruction in SPIROMICS. Am J Respir Crit Care Med. 2017;195:464-72.

32. McFadden ER Jr, Linden DA. A reduction in maximum mid-expiratory flow rate. A spirographic manifestation of small airway disease. Am J Med. 1972; 52(6):725-37.

33. Gelb AF, Zamel N. Simplified diagnosis of small-airway obstruction. N Engl J Med. 1973;288:395-8.

34. van den Berge M, ten NHT H, Cohen J, Douma WR, Postma DS. Small airway disease in asthma and COPD: clinical implications. CHEST. 2011;139:412-23.

35. Smith BM, Hoffman EA, Rabinowitz D, Bleecker E, Christenson S, Couper D, Donohue KM, Han MK, Hansel NN, Kanner RE, Kleerup E, Rennard S, Barr RG. 
Comparison of spatially matched airways reveals thinner airway walls in COPD. The multi-ethnic study of atherosclerosis (MESA) COPD study and the Subpopulations and intermediate outcomes in COPD study (SPIROMICS). Thorax. 2014;69:987-96.

36. Mets OM, de Jong PA, van Ginneken B, Kruitwagen CLJJ, Prokop M, Oudkerk M, Lammers J-WJ, Zanen P. CT air trapping is independently associated with lung function reduction over time. PLoS One. 2013;8:e61783.

37. Bommart S, Marin G, Bourdin A, Molinari N, Klein F, Hayot M, Vachier I, Chanez P, Mercier J, Vernhet-Kovacsik H. Relationship between CT air trapping criteria and lung function in small airway impairment quantification. BMC Pulm Med. 2014;14:29.

38. McDonough JE, Yuan R, Suzuki M, Seyednejad N, Elliott WM, Sanchez PG, Wright AC, Gefter WB, Litzky L, Coxson HO, Paré PD, Sin DD, Pierce RA, Woods JC, McWilliams AM, Mayo JR, Lam SC, Cooper JD, Hogg JC. Smallairway obstruction and emphysema in chronic obstructive pulmonary disease. N Engl J Med. 2011;365:1567-75.

39. Hogg JC, Chu F, Utokaparch S, Woods R, Elliott WM, Buzatu L, Cherniack RM, Rogers RM, Sciurba FC, Coxson HO, Paré PD. The nature of small-airway obstruction in chronic obstructive pulmonary disease. N Engl J Med. 2004; 350:2645-53,

40. Verbanck S, Schuermans D, Meysman M, Paiva M, Vincken W. Noninvasive assessment of airway alterations in smokers. Am J Respir Crit Care Med. 2004;170:414-9.

41. Pirozzi CS, Paine R, Tashkin DP, Kleerup EC, Woodruff PG, Han MK, Quibrera PM, Carretta E, Kanner R: Evidence of Clinical COPD in Smokers with Airway Obstruction Diagnosed with $\mathrm{FEV}_{1} / \mathrm{FVC}$ Ratio of Less than 0.70 but Not Less than Predicted Lower Limit of Normal. In American Thoracic Society International Conference Abstracts. American Thoracic Society; 2015:A4473-A4473.

42. Pirozzi CS, Gu T, Quibrera P, Carretta E, Han MK, Murray S, Cooper CB, Tashkin DP, Kleerup EC, Hoffman EA, Martinez C, Christenson S, Hansel NN, Barr RG, Bleecker ER, Ortega VE, Martinez FJ, Kanner RE, Paine R: Heterogeneous Burden of Emphysema and Functional Small Airway Abnormalities in Smokers with FEV 1 /FVC Ratio Above Lower Limit of Normal but Below 0.7. In American Thoracic Society International Conference Abstracts. Am J Respir Crit Care Med 2018;197:A6397

Ready to submit your research? Choose BMC and benefit from:

- fast, convenient online submission

- thorough peer review by experienced researchers in your field

- rapid publication on acceptance

- support for research data, including large and complex data types

- gold Open Access which fosters wider collaboration and increased citations

- maximum visibility for your research: over $100 \mathrm{M}$ website views per year

At $\mathrm{BMC}$, research is always in progress.

Learn more biomedcentral.com/submissions 